\title{
Editorial
}

\section{Gerhard Hackl}

\author{
ASMET, Leoben, Austria
}

Accepted April 21, 2021; published online May 6, 2021

ASMET, the Austrian Society for Metallurgy and Materials, invited decision-makers, engineers, developers, industry experts, scientists, and students to the fifth Metal Additive Manufacturing Conference-MAMC 2020-with the main focus on the processing of metals.

Although this was already the fifth conference out of the very successful MAMC-series, the organization was very challenging because of the Covid19-pandemic. The conference had to be organized as a virtual conference from September 30th till October 2nd, 2020. Like in the previous years, the organization committee had planned a physical conference in Vienna. Due to the strongly increasing numbers of infected people in Vienna and due to travel restrictions from European countries, the second attempt was a hybrid version, which was then changed to a purely virtual conference.

The virtual version of the 5 th MAMC-event attracted over 100 participants from more than 10 countries. The technical programme consisted of 46 oral presentations showing the latest trends and innovative developments along the entire additive manufacturing process chain as well as numerous novel applications. Compared to the last MAMCevents, these were approximately $50 \%$ of the participants and presentations.

As an online web tool, Hopin was used for the conference. This software enabled us to offer onsite virtual conference places to our sponsors for attracting participants to visit their company. On the other side, virtual discussion rooms after each session were available, which offered the speakers and conference participants the opportunities to have intense discussions. A special thank you goes to our scientific chairs for moderating the conference and directing the question and answers for every single presentation. Due to the fact this was the first virtual conference for ASMET, most presentations were pre-recorded. We were quite pleased with the performance of the conference, which was also confirmed by the feedback we received from our participants.

Another reason for the success of the 5th MAMC was the very interesting scientific programme, which was organized together with the scientific committee of the conference Professor Franz Haas, Professor Herbert Danninger, Professor Jürgen Stampfl and Prof Nadir Asnafi. The scientific programme covered the following main topics:

- Powder for MAM

- Laser Melting, Electron Beam Melting \& Direct Energy Deposition Processes

- AM Process- and Quality Control

- Post-processing of AM parts

- Tools, Space and Aircraft, Automotive, Medical and others

- Recent Research Topics

Out of these very interesting scientific areas, four papers have been chosen dealing with the topic Tooling and Tooling Applications. The paper of Professor Nader Asnafi gives an overview about the state of the art for Tooling and Tooling Applications in additive manufacturing. After these four papers, the remaining articles describe the challenges when 3D-printing of complex materials has to be performed.

\footnotetext{
G. Hackl ( $\square)$

ASMET,

Leoben, Austria

gerhard.hackl@asmet.org
} 
Further details of the presentations can found in the conference proceedings, which can be ordered from ASMET (please contact yvonne.dworak@asmet.at).

We ask you already today to reserve the date for the 6th MAMC in your diary. The 6th Metal Additive Manufacturing Conference-MAMC2021-will take place November 3rd-5th, 2021, in Vienna (Austria).

Gerhard Hackl Yvonne Dworak

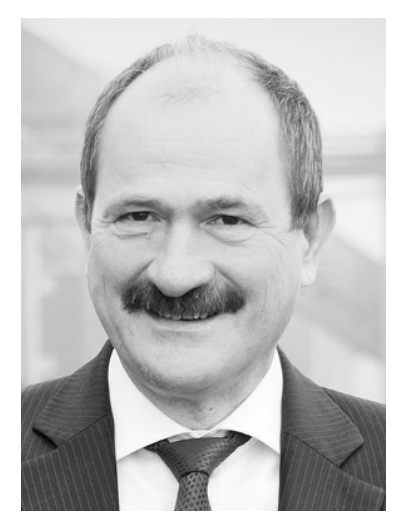

Gerhard Hackl 